\title{
O JOGO COMO EXPERIÊNCIA ESTÉTICA: APRENDIZAGENS DE UM CORPO BIOGRÁFICO NA FORMAÇÃO DE PROFESSORES
}

\author{
Andrisa Kemel Zanella \\ Cândice Moura Lorenzonii ${ }^{\mathrm{ii}}$ \\ Camila Borges Santos ${ }^{\mathrm{iii}}$
}

\begin{abstract}
Resumo: Neste artigo buscamos problematizar como o corpo biográfico pode ser mobilizado no contexto da formação de professores, a partir da vivência com jogos teatrais. O objetivo é fazer provocações pensando nesse corpo biográfico que ao jogar vivencia a possibilidade da experiência estética. $O$ ponto de partida para esta escrita é a nossa experiência como atrizes, em nossa formação inicial e como professoras de Cursos de Graduação em Pedagogia e Teatro Licenciatura de duas instituições públicas de ensino superior. Neste sentido, em nossos processos pedagógicos, artísticos e docentes, o corpo, o teatro, a experiência estética aparecem como mola propulsora para (re)pensarmos nossos modos de fazer e de agir na educação. Estes aspectos são motes para aprofundarmos a discussão aqui proposta.
\end{abstract}

Palavras-Chave: Corpo Biográfico; Jogo; Experiência Estética; Formação de Professores; Educação.

\section{THE GAME AS AESTHETIC EXPERIENCE: LEARNINGS OF A BIOGRAPHICAL BODY IN TEACHERS TRAINING}

\begin{abstract}
In this article, we seek to problematize how the biographical body can be mobilized in the context of teachers training, based on the experience with theatrical games. The aim is to make provocations thinking about this biographical body that when playing sees the possibility of aesthetic experience. The starting point for this writing is our experience as actresses, in our initial training and as teachers of Undergraduate Courses in Pedagogy and Theater from two public higher education institutions. In this sense, in our pedagogical, artistic and teaching processes the body, the theater, the aesthetic experience appear as the driving force for (re)thinking our ways of doing and acting in education. These aspects are motives for deepening the discussion proposed here.
\end{abstract}

Keyword: Biographical Body; Game; Aesthetic Experience; Teachers training; Education.

Palavras iniciais: sobre o que está em jogo

Então decidimos jogar para saber qual ponto seria o começo. Tínhamos três pedras coloridas, as quais correspondiam a enunciados. Uma de nós foi escolhida para vendar os olhos e lançar aleatoriamente as pedras para o alto. Ao ouvir o som das pedras caírem sobre a mesa, aventurou-se a tatear a superfície até que seus dedos encontraram uma das pedras. Então perguntou: qual é a cor? (silêncio) Sem esperar a resposta, rapidamente retirou o pano que lhe cobria os olhos e constatou que era a pedra 


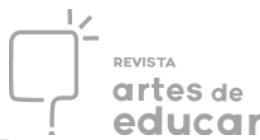

transparente. Entreolhamo-nos, pois, pela legenda que havíamos criado, a pedra transparente daria a chance de escolher qualquer ponto de começo. E assim foi que nos voltamos para rabiscar as primeiras palavras deste artigo ${ }^{4}$.

Iniciamos essa escrita voltando ao ponto de partida, coincidente para nós três: a formação inicial em teatro na mesma instituição de ensino. Com isso, outros pontos de intersecção foram se evidenciando à medida que nos aventuramos a unir a arte e a docência no âmbito profissional. É deste lugar, atuantes em cursos de formação de professores que teceremos esta escrita. Talvez por uma necessidade vivenciada por todas nós em momentos distintos, nas mais diversas situações, seja em formações para professores, em oficinas para atores ou mesmo com nossos estudantes dentro e fora do espaço acadêmico.

Além disso, é importante ressaltar que o corpo na formação de professores é o tema que entrelaça nossos estudos e pesquisas na pós-graduação. Diferentes abordagens, distintos caminhos metodológicos, mas sempre com a inquietação pulsante sobre esse talvez desconhecido: corpo e suas possibilidades. Ou como aborda Sant'Anna (2004, p.107) entendê-lo é um eterno desafio, controlá-lo uma tarefa infinita. Frequentemente vasculhado nunca com tudo totalmente compreendido.

Essa não-compreensão deve-se ao fato de que cada corpo, com sua biografia, revela uma vastidão de sentidos, construídos na e pela experiência vivida, somando-se a todo um repertório herdado dos que os antecederam. Tudo isto fica registrado no corpo como uma escritura $^{5}$, repercutindo em modos de ser, fazer e estar no mundo. E como mobilizar este corpo biográfico? Nós optamos por investir no jogo teatral, como elemento provocador de criação e atuação no aqui-agora, que repercute na docência, e consequentemente, na possibilidade de acontecimento da experiência estética, que nessa abordagem trazemos a partir de um olhar voltado para o sensível, que não está atrelado somente ao sentido ligado ao belo, como preconizado no século XVIII, conforme nos indica Hermann (2010). A partir de Gadamer (2015), a autora afirma que a experiência estética trata de um acontecimento, de um encontro, um processo revelador que descobre a realidade como um acontecer (HERMANN, 2010, p. 115), podendo provocar um abalo, uma sensação de suspensão.

Em se tratando de processos formativos, criativos, isso também pode se dar com o sujeito em estado de jogo, assim como na própria aula, ou no estar em cena. Segundo Desgranges (2006, p.110), pelo jogo há a construção do conhecimento e da compreensão artística, a qual possivelmente poderá viabilizar a experiência estética. O autor recorre ao método de Viola Spolin ${ }^{6}$ para dizer que:

Revista Interinstitucional Artes de Educar. Rio de Janeiro, V. 5, N.3- pág. 565-580 set-dez de 2019: "Educação: Corpo em movimento." - DOI: 10.12957/riae.2019.45790 
Spolin, tomando por base os jogos de regras, cria um sistema de exercícios para o treinamento do teatro, com o objetivo inicial de libertar a atuação de crianças e amadores de comportamentos rígidos e mecânicos em cena. Este sistema de atuação, calcado em jogos de improvisação, tem o intuito de estimular o participante a construir um conhecimento próprio acerca da linguagem teatral, através de um método em que o indivíduo, junto com seu grupo, aprende a partir da experimentação cênica e da análise crítica do que foi realizado. Os participantes do processo, assim, elaboram coletivamente o conceito acerca das suas atuações e da sua compreensão da linguagem teatral (DESGRANGES, 2006, p.110).

Entendemos que a interlocução entre jogo e corpo biográfico, o qual tomamos por corpo visível e singular, se dá, não somente devido ao que lhe constitui fisicamente, mas pelos olhares, gestos, pelo que compartilha com outros corpos. Essas particularidades fazem com que a mobilidade humana torne-se significativa a partir de sua própria presença corporal expressiva no mundo, não podendo ser apenas da ordem física e biológica, mas sim, sensível e criativamente potente.

As reflexões aqui propostas vêm num sentido de amadurecimento do vivido, imersos nessas trajetórias que mesclam o corpo e a formação de professores, por meio do jogo teatral. Deste modo, acenamos com nossas primeiras considerações, e então perguntamos: que corpo é esse que joga na formação de professores?

\section{Jogo e experiência estética: que corpo joga na formação de professores?}

Para elucidar o pensamento que nos motiva sobre esse corpo atuante, que joga, partimos do entendimento do corpo como meio de contato com o mundo que se apresenta em primeiro plano. Corpo onde estão inscritas regras, normas e valores de uma sociedade específica, fazendo com que cada indivíduo o construa diferentemente, por ser produto da cultura e não das semelhanças biológicas universais (DAOLIO, 1995).

Campelo (1996) endossa essa ideia ao dizer que, quando lemos o corpo de um homem, de qualquer grupo social, podemos considerá-lo tal como um texto, pois é possível captar ali os vestígios do seu contexto social. É esse corpo concreto que singulariza o sujeito no mundo. Para Gonçalves (1997), o corpo é “um campo de presença”, e por isso, está imbricado nas relações com a sociedade na qual atua. Um corpo aprendente nas ações culturais, que ocupa lugar no espaço, constrói relações, faz-se singular por um conjunto de 


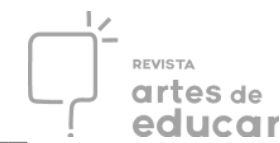

gestos, de movimentos que representam valores e princípios herdados culturalmente, através da tradição. Tais aspectos reportam a um corpo que funciona em totalidade, em que todas as camadas que o compõe, desde os aspectos físicos até os de ordem psíquica, estão implicadas em um trabalho conjunto.

Desta maneira, o corpo já é, desde o primeiro momento, uma máscara reveladora, uma personagem, trazendo impressões em seus genes de informações determinantes de uma parte da história do seu vir-a-ser (CAMPELO, 1996, p. 66). Isso significa que o corpo aprende as ações socialmente construídas, faz-se único e, por mais que seja familiar, ele é, na mesma proporção, um enigma, não só devido ao que lhe constitui fisicamente, mas aos olhares, gestos, ao que compartilha com outros corpos.

O homem enquanto unidade complexa é impactado em todas as esferas na corporeidade como ser inteligente, livre, ético, social e político e, não menos, sensível e afetado por todas essas dimensões, insere-se no mundo (GONÇALVES, 1997, p.104). Merleau-Ponty (2011) complementa essa ideia ao indicar que a corporeidade constitui-se como dimensão do homem ser/estar no mundo, e reforça que atentar para essa dimensão significa a busca de uma vida essencialmente humana. Isso leva a crer que o homem existe de forma integral e assim deve ser visto. Com isso o autor reflete sobre o fenômeno da percepção que encontra, na consciência, o sentido do corpo na relação homem-mundo: $A$ descoberta do corpo reflexivo e observável leva a crer que a experiência inicial do corpo consigo mesmo é uma experiência em propagação e se repete na relação com as coisas $e$ com os outros (MERLEAU-PONTY, 2011, p.11).

Portanto, contrariando os inúmeros dualismos impostos pelo pensamento racional e cartesiano $^{7}$, herança da modernidade, corroboramos com a ideia de que o corpo não se separa da mente e nesse viés, a reflexão de Merleau-Ponty nos conduz a um caminho que trilhamos nesta escrita a partir do entendimento de que todas as considerações lançadas até aqui são acolhidas por um sentido mais amplo. Sentido que caracteriza o que entendemos por corpo no viés biográfico:

Corpo como um manancial racional e não-racional de impulsos para a ação. Por ser possuidor de sentidos, emoções, sentimentos, afetos, imagens, símbolos e valores decorrentes do trajeto antropológico $^{8}$ de cada sujeito traz os vestígios da história individual e também da história da humanidade" (ZANELLA, 2013, p.61).

Para Josso (2012, p. 27), abordar o corpo biográfico permite o acesso a esse corpo falante de minha história passada, presente e futura, através das sensações, das imagens, Revista Interinstitucional Artes de Educar. Rio de Janeiro, V. 5, N.3- pág. 565-580 set-dez de 2019: "Educação: Corpo em movimento." - DOI: 10.12957/riae.2019.45790 


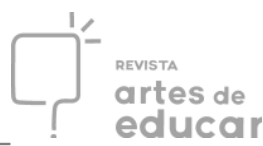

das visões animadas - espécies de sonhos acordados - das reminiscências, mas também das ideias e das escolhas [...]. Neste sentido, o corpo do qual falamos é o corpo das vivências, das experiências ${ }^{9}$, das lembranças e das memórias, as quais estão impressas nesta massa orgânica sensível e potencialmente criativa. Isto é, corpo que armazena nossa memória mais arcaica (LELOUP, 1998) e é fundamental na relação de cada pessoa com o universo que a cerca. Assim, o corpo biográfico concretiza-se na concepção de corpo-memória associada às experiências mais significativas na vida de cada indivíduo, gerando mudanças por sensibilizar o estado afetivo e emocional de cada um.

Esse potencial do corpo em criar é definido por Vianna e Castilho (2002, p. 26) ao dizerem que:

o corpo cria. Cria a si mesmo, quando refaz suas estruturas, quando se modifica, quando metaboliza alimentos. Cria as relações à sua volta, quando ocupa um lugar no espaço, se "achata" ou se expande, quando se expressa de forma verbal e não verbal. Cria tensões e desejos, de alcançar algo, tocar em alguém, se retrair, agredir, fugir, acarinhar. Cria situações expressivas, quando dança, canta, representa, gesticula, imita, mimetiza. E cria fatos. Gera conhecimento. Gera emoções. Cria doenças. Cria saúde.

Isto é, o corpo é uma composição orgânica criativa que cria/transforma a todo o momento, nas mais variadas situações do cotidiano.

Nesta perspectiva, as autoras (VIANNA; CASTILHO, 2002) também apontam que nossa primeira casa desde que nascemos, antes mesmo de morar em qualquer lugar, é o nosso corpo. Ainda questionam "quem é o "morador” de seu corpo? Seus órgãos, seu humor, seus afetos, sua memória, suas emoções, sua inteligência...". Nesse "lugar casa-corpo" fica acumulado tudo o que é significativo para nós e que nos impulsiona a agir cotidianamente, entretanto, a reflexão necessária aqui é: será que nos sentimos bem e à vontade nessa casacorpo?

A partir dessa análise sobre nossa "casa-corpo", é possível pensar que ela foi sendo construída ao longo da nossa história, mas que não é fixa, rígida e ortodoxa: pode ser flexível e sensível, se atentarmos nossa percepção para este conjunto energético e criativo que é o corpo. De modo que, estar presente em seu próprio corpo é o primeiro passo para quem se deseja mais livre, mais criativo, mais consciente de si, dos outros, do lugar que ele ocupa (VIANNA; CASTILHO, 2002, p. 23), sendo, portanto, elemento fundamental ao falarmos de processo formativo para a futura docência.

Soma-se a isso a discussão da presença do corpo no tempo e no espaço, corpo Revista Interinstitucional Artes de Educar. Rio de Janeiro, V. 5, N.3- pág. 565-580 set-dez de 2019: "Educação: Corpo em movimento." - DOI: 10.12957/riae.2019.45790 
constituído por sua biografia, com olhar atento para as singularidades de cada sujeito. Josso aponta que é pela mediação de nossos cinco sentidos que apreendemos primeiramente a nós mesmos, depois aos outros e ao nosso meio ambiente humano e natural (JOSSO, 2010, p. 76).

Neste contexto o que é viver e o que é existir? Pensamos que a vida nos é dada, está posta e a existência são as marcas que deixamos, através do jeito, das ações, das formas, ou seja, a existência em vida é o corpo como volume sensível em eterna expansão, como uma necessidade natural que nos é dada como a vida.

Estamos, em certa medida, amordaçados, represados, achatados na contemporaneidade, pois perdemos a naturalidade de nossa singularidade da vida, da nossa potência criadora, do fruir da nossa existência. Faz-se necessário assim, movimentos de reflexão, de retomada, de respeito, de abertura de espaços e de tempos para legitimarmos o corpo e sua biografia.

Rubem Alves, quando fala sobre acontecimento poético, convoca o corpo e nos diz que o acontecimento poético é assim:

o corpo ouve a música, percebe a beleza. Experiência de graça. Deseja comunicá-la. Procura palavras, sons, em cujo côncavo a beleza aconteça. Um outro corpo as ouve. Eventualmente esse ouvir provoca nele, corpo, uma ressonância. Se o corpo ressoar musicalmente, é porque existe uma identidade entre aquele que disse e aquele que ouviu (ALVES,2014, p. 13).

As palavras do autor se enlaçam com nosso pensar sobre o corpo biográfico que ao jogar cria relações e reverbera em outros corpos. Podemos dizer que para nós esse lugar já é um pouco conhecido, pois a prática do jogo é elemento fundamental em nossa formação. Aprendemos desde o começo de nossa formação a reconhecer e valorizar o lugar do jogo, e com isso, o corpo que está em jogo. Esse corpo compreendido enquanto "casa", conforme apontado anteriormente, é o instrumento do ator/professor. Ao fazer um recorte sobre o teatro especificamente, podemos dizer que o corpo é objeto de investigação e experimentações constantes, pois ele é fator desencadeante do envolvimento do espectador e determinante da intensidade da relação teatral.

Tal se dá porque o ator possui uma prática que coloca seu corpo em exercício, transformando-o em um sistema metafórico que provoca a imaginação do espectador. $\mathrm{O}$ corpo do ator é o intercessor de uma presença, pois consideramos que este carrega um personagem que, mesmo antes de pronunciar qualquer palavra, já comunica: uma série de informações flui através de sua presença no espaço cênico.

Revista Interinstitucional Artes de Educar. Rio de Janeiro, V. 5, N.3- pág. 565-580 set-dez de 2019: "Educação: Corpo em movimento." - DOI: 10.12957/riae.2019.45790 


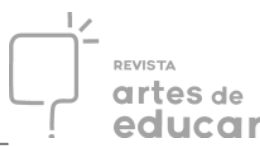

Porém ao voltar a atenção para o corpo do professor e ao transportá-lo para outro contexto, a prática pedagógica na sala de aula, onde a plateia é seu aluno - recorre-se ao repertório vivencial de cada sujeito, na busca por encontrar-se, descobrir-se e então mobilizar-se. O corpo é o próprio suporte do jogo teatral, constitui-se como cenário de saberes e práticas sistemáticas. Deste modo, entendemos que o jogo pode ser um modo de um corpo estar com outros corpos.

Compartilhamos com o leitor um pouco desse universo, informando que turmas de estudantes, muitas no contexto da formação de professores, que estão nos cursos de teatro e pedagogia recorrem a atividades com jogos. Pelo jogo vai-se constituindo um corpo disponível ao mesmo tempo percebido como potência criadora. O jogo passa a ser condição de comunicação, de fazer do corpo um corpo pensante, um corpo que comunga com outros corpos.

Um exemplo disso foi vivenciado em uma turma do Curso de Pedagogia. Ao propor jogos direcionados para a exploração corporal, muitas foram as vezes que os estudantes compartilharam memórias que haviam decorrido das atividades realizadas. Memórias relacionadas a imagens de acontecimentos vividos, que proporcionavam entrar em contato com os sentimentos adormecidos e os gestos não habituais, visibilizando as experiências que foram significativas em sua vida. A partir desse trabalho, observou-se o quanto o corpo biográfico era mobilizado. O contato com as memórias que emergiam do corpo causava um impacto e uma transformação perceptiva dos estudantes sobre si mesmos e seus corpos, repercutindo em sua atitude nas aulas e no $\mathrm{Curso}^{10}$.

Faz-se importante ressaltar que a formação de professores, especificamente na fase inicial, se constitui como um campo em que os saberes experienciais são articulados aos fundamentos teóricos, consolidando a base para a docência. É o momento em que acontece, segundo Imbernón (2006, p.65) a "socialização profissional e (da) assunção de regras $e$ princípios" na construção do "ser" professor. Sendo assim, é importante considerar que o conhecimento dos professores não é somente acadêmico, racional, tampouco somente experiencial, porém é um saber que consiste em conduzir a informação disponível e adequála, estrategicamente, ao contexto da situação formativa em que se situam, a cada instante, os objetivos traçados. É um saber agir em situação (ALARCÃO, 2003).

É nesta etapa que se faz necessário, também, problematizar a importância do corpo e de sua biografia na constituição da identidade docente. Isto porque nos vinculamos à ideia de corpo como "habitáculo" (JOSSO, 2009), ou seja, como matéria em que as 
experiências ficam registradas, a partir de um processo de assimilação e acomodação do meio, repercutindo nos gestos como vestígios do que o vivido produziu no sujeito. Na sequência, recorremos às contribuições de Nóvoa (1992), cujas ideias são corroboradas pela autora, quando ele aponta que a maneira do professor ensinar está atrelada diretamente aos seus referenciais, ou seja, às suas construções pessoais.

Assim, abordar o corpo biográfico na formação de professores, a partir de uma prática com jogos teatrais, abre caminho para trabalhar com outras percepções que emergem da experiência vivida no aqui-agora, podendo configurar-se como experiência estética.

A compreensão que temos do mundo é questionável, já que baseada em experiências também questionáveis, segundo Gadamer (2015). Nesse sentido a experiência estética desperta curiosidade a ponto de gerar um deslocamento de sentido, pois ela não necessita de critérios científicos para acontecer, ou seja, ela está associada aos afetos, às sensações, às emoções. Neste sentido, vemos o corpo como templo dos nossos afetos, nossos sentimentos, que ao ser mobilizado pelo jogo enriquece nossa natureza humana e nossa prática pedagógica.

Desta maneira concordamos com Ryngaert (2009) ao afirmar que o sujeito incapaz de jogar, no sentido mais amplo, seria o sujeito que sinaliza que conhece previamente todas as respostas e soluções, pois só considera sua relação com o mundo externo por meio de formas premeditadas e estabelecidas. Desafiando-nos a pensar num sujeito que não se dispõe a novas experiências e isso indica uma negação ao por-vir, fechamento à oportunidade de ir ao encontro do risco e do inusitado.

Portanto ao se dispor ao jogo e entregar-se ao instante, em presença, o sujeito abre-se para uma escuta que o coloca receptivo ao outro, mesmo sem manter contato visual. Convoca a presença do corpo no instante do acontecimento, se desenhando como espaço de encontros e trocas. Isso nos provoca a pensar que o corpo que "está em jogo" pode criar possibilidades de acessar e construir saberes que partem da dimensão biográfica de cada sujeito para conjugar-se com outros saberes da esfera formativa. Já que "o espaço do jogo, como espaço potencial, é um lugar no qual se experimenta a escuta do outro, como tentativa de relação entre o dentro e o fora" (RYNGAERT, 2009, p. 66).

Neste sentido, trazemos um recorte de experiência vivida dentro de um grupo de pesquisa $^{11}$, a partir de alguns jogos voltados para a sensibilização do corpo, a interação com o espaço e a relação com o outro, os quais mobilizaram o corpo biográfico. Com a 


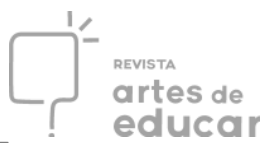

experimentação do corpo, os participantes aguçaram sua percepção sobre as relações criadas, os afetos, o fluxo do movimento, a criatividade e, principalmente, a cumplicidade durante o jogo, pois cada participante estava atento à movimentação do outro, construindo uma atuação corporal viva, singular e no coletivo. A prática e o convívio, voltados para estas vivências, além de sensibilizar o corpo geram possibilidades criativas, abrindo caminhos para a consciência corporal, estimulando uma escuta interna e que, pela presença e pela provocação do corpo do outro, leva à busca pelo autoconhecimento e pela construção da autoimagem.

Nesta perspectiva, o sentir e viver o corpo que joga ganham sentido e passam a ser conteúdo da formação para a docência abarcando a subjetividade que perpassa a conduta humana, pois o jogo se encontra no movimento em curso, onde segundo o autor sempre existe: “de forma desigual, invenção e reinvenção” (RYNGAERT, 2009, p. 66).

Spolin $(2008$, p. 5) aponta que a energia desprendida no ato do jogo para solucionar os obstáculos que o jogo propõe, pela própria constituição do grupo, cria uma explosão, onde tudo é "destruído, rearranjado, desbloqueado"; isso faz com que o corpo esteja diretamente implicado como um todo orgânico, que participa de um algo maior que é o próprio jogo. A autora chama esse funcionamento de experiência integrada, onde o sujeito se apresenta de forma total como potência criadora e comunicadora dentro do jogo.

Para o jogo se faz necessário estar em jogo, é condição fundamental estar aberto para o acontecimento que o jogo engendra. Supõe uma escuta para o outro que está presente. Estar presente é estar aberto para o que possa vir. Isso exige estar atento para receber e perceber o que acontece. Afetar e deixar-se afetar.

Neste seguimento, pensar a formação por essa ótica nos impele a trazer para a discussão a ideia de Carpim (2014). Para essa autora a formação é um processo contínuo e que requer uma caminhada investigativa sistemática e dialógica (CARPIM, 2014, p. 73). Podemos ampliar essa reflexão e pensar que é durante esse percurso que o sujeito, futuro professor, tem a oportunidade de atribuir um novo sentido às experiências vividas, pela maneira que é provocado em sua formação.

Mesmo no Curso de Pedagogia em que não há tanto espaço para a expressão do corpo, vemos que o jogo cria um cenário potente para a criação, invenção, disponibilidade, ressignificando relações entre o sujeito e si mesmo, o sujeito e o outro, o sujeito e o espaços. Isto porque nas palavras de Brazil (1988, p.79)

ao jogo não é possível impor modelos, em nome dos quais a ordem se legitima e aperfeiçoa seus meios de influência e produção. O jogo é uma via, e, no seu percurso, se constituem as significações do sujeito. $O$ jogante, mesmo seguindo regras 
estando referido a algo externo - o brinquedo-, dispõe-se à incerteza, à possibilidade e ao risco.

No trabalho do ator, do diretor e nas turmas de pedagogia onde atuamos, percebemos que o jogo se faz implícito. Recorremos à Huizinga (1972, p. 54), na obra Homo Ludens, quando ele diz: É sempre possível que a qualquer momento, mesmo nas civilizações mais desenvolvidas, o 'instinto' lúdico se reafirme em sua plenitude, mergulhando o indivíduo e a massa na intoxicação de um jogo gigantesco.

Considerar a plenitude que pode ser proporcionada ao sujeito que joga convidado a um estado de atenção e inteireza, pela atmosfera que é criada para que o jogo seja um acontecimento no aqui e agora, nos leva a citar novamente Ryngaert (2009, p. 34) que anuncia o jogo como experiência sensível, experiência artística e relação com o mundo. $\mathrm{O}$ autor afirma ainda que, o homem que joga se propõe a se experimentar, e isso possibilita suas relações com o mundo. Numa perspectiva de formação portanto

a aptidão para o jogo é uma forma de abertura e de capacidade para se comunicar. Ela desenvolve a conscientização de novas situações e um potencial de respostas múltiplas, ao invés de um recuo a terrenos familiares e da aplicação sistemática de estruturas pré-existentes (RYNGAERT, 2009, p. 61).

Spolin (2008, p. 5) também nos dá subsídios à elaboração do nosso pensamento em relação à formação ao colocar que

experienciar é penetrar no ambiente, é envolver-se total e organicamente com ele. O que condiz com todos os níveis: intelectual, físico e intuitivo, sendo o intuitivo o mais vital para a situação de aprendizagem. Quando o nível intuitivo reconhece respostas dadas às experiências, ela está aberta a aprender.

Deste modo jogar, entregar-se ao ato efêmero do que pode o jogo proporcionar, nos conduz a olhá-lo como uma ferramenta de abertura para experiência estética, tendo em vista que o sujeito imerge em um contexto artístico, que se concretiza no presente, a partir de uma ação consciente e conectada ao aqui-agora.

O jogo, como mola propulsora para a experiência estética, pode ser uma possibilidade de formação, pois proporciona ruptura e reflexão, somos afetados, atravessados e estes movimentos impulsionam a criação de outras ações, outras práticas, outros olhares e outras compreensões de mundo. Representa uma experiência que extrapola o conhecimento racional e legitima os saberes do corpo enquanto conhecimento, o que as palavras de 
Hermann (2014, p. 131) confirmam:

na medida em que abala nossas convicções comuns, esse tipo de experiência suspende as certezas e projeta uma nova estrutura de sentido. [...] Tais experiências de liberação da subjetividade cumprem um papel formativo na relação com o outro porque oportunizam vivências imaginativas e sensíveis capazes de deixar que o outro aconteça.

Neste processo, a abertura para o desconhecido, para o surgimento e o estranhamento do outro, aparecem como estímulo para os sentidos e saberes que estão submersos em cada sujeito. A experiência estética privilegia, de certo modo, o autoconhecer-se e o autocompreender-se, na relação de "diálogo" com o mundo, pois acreditamos que a reflexão sobre si leva à articulação de conhecimentos sobre a e na vida.

Para melhor esclarecer o modo possível de conexão entre o corpo, o jogo e a experiência estética e a maneira como estas dimensões se articulam, trazemos Gadamer (2015), o qual afirma que a experiência estética é análoga à questão do diálogo, pois está em constante fluxo de pergunta-e-reposta, onde quem pergunta também é questionado.

A experiência só se atualiza nas observações individuais. Não se pode conhecê-la numa universalidade prévia. É nesse sentido que a experiência permanece fundamentalmente aberta para toda e qualquer nova experiência - não só no sentido geral da correção dos erros, mas porque a experiência está essencialmente dependente de constante confirmação, e na ausência desta confirmação ela se converte necessariamente noutra experiência diferente (ubireperiturinstantiacontradictoria) (GADAMER, 2015, p. 460).

No conceito de Gadamer para a experiência, a compreensão que temos do mundo é questionável. Para isso, a experiência estética desperta curiosidade a ponto de gerar um deslocamento de sentido, pois ela não necessita de critérios científicos para acontecer, ou seja, ela está associada aos afetos, às sensações, às emoções. Neste sentido, não menosprezemos nossos afetos, nossos sentimentos, caminhemos no sentido de enriquecer nossa natureza humana. Assim, apostamos na força do jogo e de todos os elementos que ele mobiliza no sujeito que se dispõe a vivenciá-lo, como recurso que pode transbordar para a formação de professores e repercutir nas atividades de ensinar e aprender, bem como possibilidade de fazer acontecer a experiência estética, ao entendê-la como algo que não ocorre separada do corpo, mas sim, é acionada por ele. 


\section{Reflexões em movimento}

Um dos grandes desafios atuais da formação de professores profissionais é a mudança dos fundamentos do paradigma que orienta a formação de professores [...] para um paradigma que reconhece a interdependência existente entre os processos de pensamento, de construção do conhecimento e do vivido (em seu amplo espectro); que colabora para resgatar a visão de contexto e não para separar o indivíduo do mundo em que vive e de seus relacionamentos (PERES, 2006, p.61-62).

O fragmento da autora nos incita a pensar que a produção de saberes se dá pela prática e pela maneira que as vivências ao serem refletidas transformam-se em experiências formativas (JOSSO, 2004), rompendo com a produção do conhecimento focado na imobilidade e racionalidade dos corpos, compreendendo que a vivência com jogos pode ser mobilizadora de um corpo biográfico que se faz existir e se legitima nos desdobramentos que se articulam pela sua inteireza, oposta a fragmentações e dualismos. Pois ao jogo cabe proporcionar movimento, forma, visibilidade e voz aos docentes em sua prática profissional. Produzir a vida do professor implica valorizar, como conteúdos de sua formação, seu trabalho crítico-reflexivo sobre as práticas que realiza e sobre suas experiências compartilhadas (PIMENTA, 2002, p. 29).

Produzimos a vida pelas vivências, experiências, acontecimentos, pelas tramas das relações com nossos familiares, amigos, colegas de trabalho e com o mundo em nossa volta, também nos encontros, nas alegrias, nos afetos, nos rompimentos, nos desenlaces, no sofrimento, nas conquistas. Não há linearidade em uma história de vida: há caminhos sinuosos e incertos.

Tentamos ter as rédeas de novas vidas, assumimos os riscos, sustentamos e repensamos decisões, no entanto e queremos dizer na maior parte das vezes, a vida é atravessada por acontecimentos que não são determinados por nós, eles apenas acontecem. Não estamos sós, produzimos juntos-no-mundo-com ${ }^{12}$, um bem viver, um mal viver, não queremos atribuir juízo de valor, mas acreditamos que pensar como e de que modo produzimos a nossa vida, pode ser um caminho para mobilizar os corpos, os nossos e o dos outros, em alguma medida, incluindo o jogo no caminho da experiência estética.

Neste viés o professor formador assume um papel importante na mobilização do corpo biográfico que, ao jogar, vivencia a possibilidade da experiência estética, conforme anunciamos como objetivo deste artigo. Nesta perspectiva o formador constitui-se segundo Nóvoa em um ser pensante e sensível que se convoca na sua construção pessoal e caminhada 
do formador na sua relação com os outros, ajudando-os a mobilizarem-se para o processo formativo (NÓVOA, 2010, p. 24).

Problematizar a formação a partir da prática com jogos teatrais possibilitou experimentar outros modos de construir saberes em relação à docência. Saberes que extrapolaram a ideia de instrumentalização para apostar na formação pessoal e humana do professor, o que significou não aguardar um único desdobramento, mas a diversidade de manifestações de um corpo que traz inscrito em si todo um repertório de vida.

Compreendendo que a formação acontece pelas experiências, pelas reflexões de si e na relação com os outros e com o mundo, enfocar o jogo e a experiência estética no contexto formativo pode ser um caminho para amplificar as habilidades e possibilidades de qualificação da formação docente, a partir de outros paradigmas que perpassam a invenção, a imaginação e a presença. Elementos que se materializam no aqui-agora e na produção de sentidos, saberes e outros maneiras de fazer e estar no contexto formativo.

Diante do exposto, perguntamos: o jogo como elemento formativo e experiência estética poderia ser um elemento fundante na constituição do futuro professor? Ousamos dizer que sim, tendo em vista as palavras de Pacheco (1995) ao destacar que na ação dos professores está inserido um conhecimento mais intuitivo do que racional, acompanhado por decisões que são justificadas por impulsos e sentimentos, revelando um caráter de improvisação e (re)invenção nas interações pedagógicas.

\section{REFERÊNCIAS}

ALARCÃO, I. Formação Continuada como instrumento de profissionalização

docente. In: VEIGA, I. P. A. (org.) Caminhos da Profissionalização doMagistério. 3. ed. São Paulo: Editora Papirus, 2003.

ALVES, R.Variações sobre o prazer.São Paulo: Planeta, 2014.

BRAZIL, C. N. V. O jogo e a Constituição do Sujeito na Dialética Social. Rio de Janeiro: Forense-Universitária, 1988.

CAMPELO, C. R. Cal(e)idoscorpos: um estudo semiótico do corpo e seus códigos. São Paulo: ANNABLUME, 1996.

CARPIM, L. Formação continuada e a prática pedagógica do professor universitário: um fazer colaborativo. In: FERREIRA, J. L. (org.). Formação de professores - teoria e prática pedagógica. Petrópolis: Vozes, 2014. 
DAOLIO, J. Da cultura do corpo.9. ed. Campinas: Papirus, 1995.

DESGRANGES, F. Pedagogia do teatro.Provocação e dialogismo.São Paulo: Hucitec, 2006.

DORNELES, M. A.; ARENHALDT, R. Disposições ético-estético-afetivas na pesquisa em educação. In: FEITOSA, D. A. (Org.). O sensível e a sensibilidade na pesquisa em educação. Cruz das Almas: UFRB, 2016.

DURAND, G. As estruturas antropológicas do Imaginário. São Paulo: Martins Fontes, 2002.

GADAMER, H-G. Verdade e Método I: traços fundamentais de uma hermenêutica filosófica. Rio de Janeiro: Vozes, 2015.

GONÇALVES, M. A.. Sentir, pensar, agir :corporeidade e educação .Campinas: Papirus, 1997.

HERMANN, N. Autocriação e horizonte comum: Ensaios sobre educação éticoestética. Ijui: Unijuí, 2010.

Ética e educação:outra sensibilidade. Belo Horizonte: Autêntica, 2014.

HUIZINGA, J. Homo Ludens: o jogo como elemento da cultura. São Paulo:

Perspectiva, 1972.

IMBERNÓN, F. Formação docente e profissional :formar-se para a mudança e a incerteza. 6. ed. São Paulo:Cortez, 2006.

JOSSO, M-C. Experiências de Vida e Formação. São Paulo: Cortez, 2004.

. Da formação do sujeito... Ao sujeito da formação. In: NÓVOA, A.; FINGER, M. (Orgs.). O método (auto)biográfico e a formação. Natal: EDUFRN; São Paulo: Paulus, 2009.

As narrações do corpo nos relatos de vida e suas articulações com os vários níveis de profundidade do cuidado de si. In: VICENTINI, P.; ABRAHÃO, M. H. (Orgs.). Sentidos, potencialidades e usos da (auto)biografia. São Paulo: Cultura Acadêmica, 2010. . O Corpo biográfico. Corpo falado e corpo que fala. Educação e Realidade, Porto Alegre, v. 37, n.1, p. 19-31, jan./abr. 2012.

LARROSA, J. Tremores. Belo Horizonte: Autêntica Editora, 2014.

LELOUP, J-Y. O corpo e seus símbolos: uma antropologia essencial. 2. ed. Petrópolis: Vozes, 1998.

MERLEAU-PONTY, M. Fenomenologia da Percepção. São Paulo: Freitas Bastos, 2011.

NÓVOA, A. Os professores as histórias de sua vida. In: NÓVOA, A. (Org.). Vidas deProfessores. 2. ed. Porto: Porto Editora, 1992.

Revista Interinstitucional Artes de Educar. Rio de Janeiro, V. 5, N.3- pág. 565-580 set-dez de 2019: "Educação: Corpo em movimento." - DOI: 10.12957/riae.2019.45790 
Paulus, 2010.

PACHECO, J. A. O pensamento e a ação do professor. Porto: Porto Editora, 1995.

PERES, L. M. V Os caminhos e os desassossegos no tornar-se professor (a)... In: OLIVEIRA, V. (org). Narrativas e Saberes Docentes. Ijuí: Editora Unijuí, 2006.

PIMENTA, S. G. (org.).Saberes Pedagógicos e Atividade Docente. 3. ed. São Paulo: Cortez,2002.

RYNGAERT, J-P. Jogar, representar: práticas dramáticas e formação. São Paulo: Cosac Naify, 2009.

SANT'ANNA, D. B. Cultos e enigmas do corpo na história. In: STREY, M. N.; CABEDA, S. T. L. Corpos e subjetividades em exercício interdisciplinar.Porto Alegre: EDIPUCRS, 2004. p. 107-131.

SANTOS, C. B. O corpo biográfico: experiências formadoras dentro de um grupo de pesquisa. 2013. 148f. Dissertação (Mestrado em Educação) - Universidade Federal de Santa Maria, Centro de Educação, Programa de Pós-Graduação em Educação, RS, 2013.

SPOLIN, V. Improvisação para o teatro. São Paulo: Perspectiva, 2008

VIANNA, A.; CASTILHO, J. Percebendo o corpo. In: GARCIA, R. L. (org.). O corpo que fala dentro e fora da Escola. Rio de Janeiro: DP\&A, 2002.

ZANELLA, A. K. Escrituras do corpo biográfico e suas contribuições para a educação: um estudo a partir do imaginário e da memória. 2013. 218f. Tese (Doutorado em Educação) - Universidade Federal de Pelotas, Faculdade de Educação, Programa de Pós-Graduação em Educação, RS, 2013.

'Professora dos Cursos de Dança e Teatro Licenciatura do Centro de Artes da Universidade Federal de Pelotas. Doutora em Educação pela Universidade Federal de Pelotas/RS. Pelotas/RS/Brasil.andrisakz@ gmail.comhttp://orcid.org/0000-0001-9769-9679

ii Professora do Departamento de Artes Cênicas da Universidade Federal de Santa Maria. Doutora em Educação pela Universidade Federal de Santa Maria/RS, Santa Maria/RS/Brasil. E-mail: candicelorenzoni@yahoo.com.br https://orcid.org/0000-0003-4558-0435

iii Professora substituta no Curso de Licenciatura em Teatro da Universidade Federal de Santa Maria. Doutoranda em Educação pelo Programa de Pós-Graduação em Educação da Universidade Federal de Santa Maria/RS, Santa Maria/RS/Brasil.camilaborgessm@hotmail.comhttps://orcid.org/0000-0002-1629-2568

4 Trecho elaborado pelas autoras.

${ }^{5}$ Inscrições que ficam registrados no corpo, no âmbito físico e psíquico, a partir das experiências vivenciadas no decurso do trajeto de vida e que se reflete, de alguma maneira, na interação do sujeito com e no mundo (ZANELLA, 2013). 


\begin{abstract}
${ }^{6}$ Viola Spolin (1906-1994) EUA. Vinculada ao movimento de renovação que ocorreu no teatro norte-americano na década de 1960 criou, em Chicago, um sistema de atuação baseado em jogos improvisacionais (SPOLIN, 2008).

${ }^{7} \mathrm{Na}$ cultura ocidental, durante muito tempo, a razão, como estatuto de um pensamento verdadeiro e dominante, limitou a abordagem do corpo, reforçada na dicotomia entre corpo e mente instituída a partir dos estudos de René Descartes.

${ }^{8}$ Conceito do campo dos estudos do Imaginário. Para Durand (2002), o trajeto antropológico é a maneira que o sujeito assimila e acomoda as intimações, no âmbito objetivo e subjetivo, do meio cósmico e social.

${ }^{9}$ Tomamos a experiência no sentido de reflexão de si, a partir da ideia apresentada por Larrosa, o qual afirma: "a experiência, a possibilidade de que algo nos aconteça ou nos toque, requer um gesto de interrupção, um gesto que é quase impossível nos tempos que correm: requer parar para pensar, parar para olhar, parar para escutar, pensar mais devagar, e escutar mais devagar; parar para sentir, sentir mais devagar, demorar-se nos detalhes, suspender a opinião, suspender o juízo, suspender a vontade, suspender o automatismo da ação, cultivar a atenção e a delicadeza, abrir os olhos e os ouvidos, falar sobre o que nos acontece, aprender a lentidão, escutar aos outros, cultivar a arte do encontro, calar muito, ter paciência e dar-se tempo e espaço" (LAROSSA, 2014, p. 25).

${ }^{10}$ Exemplo retirado da tese de Doutorado "Escrituras do corpo biográfico e suas contribuições para a educação: um estudo a partir do imaginário e da memória" (2013), orientada pela Prof. Dra ${ }^{\mathrm{a}}$. Lúcia Maria Vaz Peres.

${ }^{11}$ Grupo de Estudos e Pesquisas em Educação e Imaginário Social - GEPEIS/ UFSM, o qual contribuiu no processo de vivência e elaboração da dissertação de Mestrado "O Corpo Biográfico: experiências formadoras dentro de um grupo de pesquisa" (2013), orientada pela Prof. Dra . Valeska Fortes de Oliveira.

12 Termo utilizado pela por Malvina do Amaral Dorneles e Rafael Arenhaldt (2016, p. 28) inspirado na compreensão de Dasein de Heidegger.
\end{abstract}

